\section{The Moon and the Barometer.}

IT is an old popular belief that weather tends to be more settled about full moon. Here are some sayings from Inward's "Weather Lore" :-

"The three days of the change of the moon from the way to the wane we get no rain " (United States).

"The weather is generally clearer at the full than at the other ages of the moon" (Bacon).

"In Western Kansas it is said that when the moon is near full it never storms."

"The full moon brings fine weather." "The full moon eats clouds." (This disappearance of cloud Mr. G. F. Chambers pronounces "a thoroughly well authenticated fact.")

The following evidence in this connection seems to me instructive. It relates to Ben Nevis (1884-1892, nine years) and Greenwich (1889-1904, sixteen years), and to the summer half only (to be more exact, the six lunation commencing with that which had full moon in April).

The method was as follows:--In the case of Ben Nevis, fourteen columns were arranged for the fourteen days ending with full moon, and fourteen for those following full moon. Each day with barometer under $25 \cdot 2$ was re-

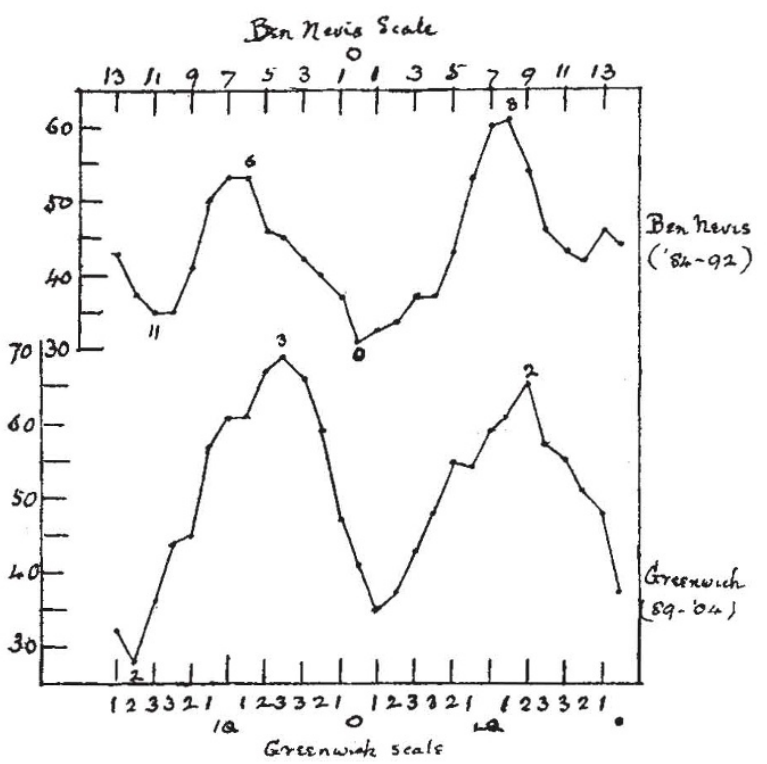

presented by a dot in those (graduated) columns; total 407. The dots in each column were then counted, and the sums obtained were added in groups of three (first to third, second to fourth, third to fifth, and so on). Thus we get the upper curve in the diagram.

In the case of Greenwich, the method was slightly different (see lower horizontal scale). The columns were for seven days about each of the four phases. For comparison with the Ben Nevis curve we commence with the first day after new moon. The days here considered were those with barometer under 29.6 inches; total, 476 .

These two curves seem to tell much the same tale; fere days of low barometer about (just after) full and new moon, many such days about (just after) the quarters. Thus, so far as the summer half in those twenty-one years is concerned, the popular belief would appear to be vindicated.

To give a fuller idea of the relations, I add a table of the maximum and minimum values (each number is, of course, the sum of three) :-

\begin{tabular}{llllllllll} 
& & \multicolumn{3}{c}{$\begin{array}{c}\text { First } \\
\text { min. }\end{array}$} & \multicolumn{3}{c}{$\begin{array}{c}\text { First } \\
\text { max. }\end{array}$} & $\begin{array}{c}\text { Second } \\
\text { min. }\end{array}$ & $\begin{array}{c}\text { Second } \\
\text { max. }\end{array}$ \\
Ben Nevis & $\ldots$ & $\ldots$ & 35 & $\ldots$ & 53 & $\ldots$ & 31 & $\ldots$ & $6 \mathbf{r}$ \\
Greenwich & $\ldots$ & $\ldots$ & 28 & $\ldots$ & 69 & $\ldots$ & 35 & $\ldots$ & 65
\end{tabular}

NO. $\{840$. vol. 7 I
It will be seen that the chief maximum is about double the chief minimum in one case, and more than double in the other.

In a dot-diagram, where each day is represented separately according to its barometer (not merely grouped with others as below a certain limit), the contrast between the phases comes out still more clearly.

The view here given apparently finds support from various quarters. In the Meteorologische Zeitschrift for I9co, p. $42 \mathrm{I}$, Herr Börnstein gives a curve of pressure for Berlin (May to August in 1883-1900) which is of similar type to those in the diagram. Fr. Dechevrens informs me that the results above given agree with those of his own observations in China, Constantinople, and Jersey. M. Sainte Claire-Deville found the same variation at Cayenne, in French Guiana.

With regard to the winter half (October to March), the régime would appear to be somewhat different, but I cannot speak definitely of it at present.

Whether the facts presented be thought to indicate lunar influence or not, it may be of interest to watch future weather (in the summer half) from the point of view suggested. Alex. B. MacDowall.

\section{Reversal in Influence Machines.}

THE method suggested for producing reversal on a Voss or Wimshurst will not be found always trustworthy. Atmospheric conditions make a great difference. I have been experimenting for more than a year with the view of finding a solution of the reversal problem, and think I have succeeded in tracing the cause, which is primarily connected with dielectric strain. A Wimshurst with the dischargers beyond sparking distance, working at full speed, will often reverse if the discharge is made by suddenly connecting the terminals, but there is no certainty in producing this effect. I have recently constructed an influence machine akin to the Voss except that the replenishment is from the back of the disc. Reversal is still the stumbling block, and must occur with fixed inductors, while no plan for controlling the reversal can be relied upon. I should be happy to give any of your correspondents fuller particulars of my experiments if they will communicate with me.

Colchester, January I4

\section{Dates of Publication of Scientific Books.}

MAY I through your columns suggest to publishersespecially of scientific and mathematical books-to give in their catalogues the dates of publication of their books? As a book often gets out of date very soon, such an addition would greatly help those who have no access to good libraries in selecting books to be purchased. I may say that this is done almost invariably in the catalogues of French and German publishers. To take an instance, the Clarendon Press still includes Price's " Infinitesimal Calculus" in its catalogue. Now, although to one who wants to study the subject in an exhaustive manner the book is very valuable, still, to one who wishes to know the principles only, the book is, to say the least, not worth the big price asked for; and if the date of publication were mentioned in the catalogue, the purchaser would at any rate know that he was not buying an up to date book.

Fergusson College, Poona, India, January I.

\section{Super-cooled Rain Drops.}

THE letter which appeared in your last issue (p. 295) from Mr. Robinson with reference to this interesting phenomenon reminds me of a similar case which I observed in Bournemouth during the winter of 1888 , and I described in NATURE at the time under the title, "Is Hail thus Formed?" (vol. xxxvii., p. 295).

Cecil Carus-Wilson. 